\title{
ENFERMARIAS MISTAS EM PSIQUIATRIA: MEMÓRIA DA ENFERMAGEM SOBRE UM NOVO ESPAÇO ASSISTENCIAL NO BRASIL
} (1996-2002)

\author{
MIXED WARDS IN PSYCHIATRY: RECORDS OF NURSING CARE ON A \\ NEW ASSISTANCE SPACE IN BRAZIL (1996-2002)
}

\author{
ENFERMERÍAS MIXTAS EN PSIQUIATRÍA: MEMORIA DE LA \\ ENFERMERÍA SOBRE UN NUEVO ESPACIO ASISTENCIAL EN BRASIL
} (1996-2002)

\author{
Maíra Nogueira e SiLVA * \\ Cynthia Haddad Pessanha Sousa ${ }^{* *}$ \\ Paloma Mello Bandeira ${ }^{* * *}$ \\ Rosane Mara Pontes de Oliveira ${ }^{* * * *}$ \\ Antonio José de Almeida Filho ${ }^{* * * * *}$ \\ María Angélica de Almeida Peres ${ }^{* * * * *}$
}

\section{RESUMO}

Objetivo: Analisar as implicações da implantação das "Enfermarias Mistas" na configuração do espaço assistencial do Instituto de Psiquiatria da Universidade Federal do Rio de Janeiro (IPUB), na visão da equipe de enfermagem. Metodo: Estudo sócio-histórico, cujas fontes primárias foram documentos escritos e documentos orais produzidos com 5 profissionais da equipe de enfermagem. Resultados: Nas Enfermarias Mistas a distribuição de doentes por sexo deu lugar a uma distribuição por quadro clínico, propiciando o surgimento de um espaço terapêutico diferenciado e facilitador da reabilitação psicossocial, denominado "enfermaria de portas abertas". A equipe de enfermagem ainda permaneceu com papéis de vigilância e controle, porém com maior liberdade para o planejamento de ações de reabilitação psicossocial. Conclusõa: As Enfermarias Mistas tiveram a equipe de enfermagem como principal agente transformador. Funcionou como estratégia de convivência sem segregação sexual, propiciando a existência de um novo espaço terapêutico, rompendo, dentro dopossível,com o modelo manicomial.

Palavras chave: Unidades de internação, história da enfermagem, saúde mental, enfermagem.

\section{ABSTRACT}

Objective: To analyze the implications of implementing "mixed wards" in the design of assistance space of the Psychiatry Institute of the Federal University of Rio de Janeiro (IPUB), from the perspective of the nursing

\footnotetext{
*Enfermeira. Universidade Federal do Rio de Janeiro, Brasil. Email: mairanogsil@gmail.com

${ }^{* *}$ Enfermeira. Universidade Federal do Rio de Janeiro, Brasil. Email: cy.haddad@gmail.com

${ }^{* * *}$ Enfermeira. Secretaria Estadual de Saúde do Estado de Minas Gerais, Brasil. Email: paloma.bandeira@ipsemg.mg.gov.br

${ }^{* * * *}$ Dra da Escola de Enfermagem Anna Nery. Universidade Federal do Rio de Janeiro, Brasil. Email: rosanemara@eean.ufrj.br ${ }^{* * * * *}$ Dr da Escola de Enfermagem Anna Nery. Universidade Federal do Rio de Janeiro, Brasil. Email: ajafilhos@gmail.com ${ }^{* * * * *}$ Dra da Escola de Enfermagem Anna Nery. Universidade Federal do Rio de Janeiro, Brasil. Email: angelica.ufrj@uol. com.br
} 
staff. Method: Sociohistorical study, whose primary sources were written and oral documents produced by 5 professional nursing staff members. Results: The distribution of patients by gender in mixed wards gave rise to a distribution by clinical presentation, which led to the emergence of a differentiated therapeutic space facilitating psychosocial rehabilitation called "open-door ward". The nursing staff still took roles of surveillance and control, but had greater freedom for the planning of psychosocial rehabilitation. Conclusion: Mixed wards worked as a strategy to cohabit without sexual segregation, allowing for the existence of a new therapeutic area, which ended, where possible, with the asylum model.

Key words: Impatient care units, history of nursing, mental health, nursing.

\section{RESUMEN}

Objetivo: Analizar las implicancias de la implementación de las "Enfermerías Mixtas" en la configuración del espacio asistencial del Instituto de Psiquiatría de la Universidad Federal de Río de Janeiro (IPUB), en la perspectiva del personal de enfermería. Método: Estudio socio-histórico, cuyas fuentes primarias fueron documentos escritos y orales producidos con 5 miembros del personal profesional de enfermería. Resultados: La distribución de pacientes por género en las Enfermerías Mixtas generó una distribución por cuadro clínico, lo que llevó a la aparición de un espacio diferenciado terapéutico y facilitador de la rehabilitación psicosocial, llamado "enfermería de puertas abiertas". El personal de enfermeira, permaneció con funciones de vigilancia y control, pero con una mayor libertad para la planificación de la rehabilitación psicosocial. Conclusión: Las salas mixtas de hospitalización tuvieron al personal de enfermería como el principal agente de cambio. Funcionó como estrategia de convivencia sin segregación sexual, lo que permitió la existencia de un nuevo espacio terapéutico, rompiendo, posiblemente, con el modelo de aislamiento.

Palabras clave: Unidades de internación, historia de la enfermería, salud mental, enfermería.

Fecha recepción: 29/06/2015 Fecha aceptación: 30/12/16

\section{INTRODUÇÃO}

O objeto de estudo é a transformação do espaço assistencial do Instituto de Psiquiatria da Universidade Federal do Rio de Janeiro (IPUB), na visão da equipe de enfermagem, após a implantação de unidades de internação mistas (Enfermarias Mistas), no período de 1996 a 2002.

O IPUB tem suas origens no Hospício Nacional de Alienados (HNA), criado no Rio de Janeiro, no século XIX. Com a transferência do HNA para o bairro do Engenho de Dentro, o seu Instituto de Psicopatologia, fundado em 1893, foi transferido para a Universidade do Brasil (UB) pelo Decreto-Lei no 591 de 1938, que criou o IPUB, sigla até hoje utilizada, apesar da mudança do nome da universidade para Universidade Federal do Rio de Janeiro (UFRJ) (1).

A década de 1990 foi marcada por fatos significativos para a história da enfermagem psiquiátrica no IPUB e na Escola de Enfermagem Anna Nery (EEAN), ambos pertencentes a UFRJ: em 1994, após dezoito anos da saída da Enfermeira Teresa de Jesus Sena, primeira professora da EEAN a ocupar a chefia de enfermagem do IPUB, outra enfermeira e professora da EEAN, Cristina Maria Loyola Miranda, passou a ocupar este cargo, apoiando as transformações assistenciais propostas pelo diretor à época, professor João Ferreira da Silva Filho, e iniciando reformulações na assistência de enfermagem, com mudanças na filosofia do cuidado para adequá-lo à proposta da Reforma Psiquiátrica (2).

A partir do movimento de Reforma Psi- 
quiátrica no Brasil, o IPUB assumiu um importante papel na elaboração do Programa de Saúde Mental da cidade do Rio de Janeiro, sendo reconhecido como Centro de Excelência em Saúde Mental do Sistema Único de Saúde (SUS) modelo de saúde em vigor no Brasil, além de Centro Colaborador em Saúde Mental para Ensino, Pesquisa e Treinamento em Serviço, da Organização Mundial da Saúde (1).

No contexto mais amplo, foi nas décadas de 1980 e 1990 que algumas mudanças decorrentes da Reforma Psiquiátrica foram implantadas no país, propiciando a ampliação de dispositivos extra-hospitalares e a criação de leis para regularizar a prestação destes serviços. A Portaria no 3.409, de 20 de agosto de 1998, criou o Programa Nacional de Avaliação de Serviços Hospitalares (PNASH), que teve como objetivo principal melhorar a qualidade dos serviços hospitalares prestados aos usuários do Sistema Único de Saúde, respeitando os princípios de universalidade e da equidade, segundo um sistema de avaliação hospitalar $(3,4)$.

Sendo assim, as instituições psiquiátricas tiveram que diminuir o número de leitos, o que viabilizava transformação em seu espaço de internação pela redução da quantidade de pacientes internados. Os anos de 1990 foi marcado pela efetiva redução dos leitos psiquiátricos, pelo fechamento de hospitais privados e pela criação de leitos psiquiátricos nos hospitais gerais e de Núcleos ou Centros de Atenção Psicossocial (4). Tal situação favorecia uma mudança para melhor na assistência prestada, uma vez que reduzia a sobrecarga de trabalho dos profissionais de saúde, enquanto possibilitava a "criação de projetos voltados para a criação de novas formas de atenção, de espaços de não exclusão, de movimento/criação e, principalmente, de espaços de ancoragem que possibilitem a constituição da singularidade e da subjetividade do usuário" (4).

Em 6 de abril de 2001 foi sancionada a Lei Federal no 10.216 , que articula sobre prote- ção e direitos dos indivíduos portadores de transtornos mentais e redireciona o modelo assistencial em saúde mental, regulamentando o cuidado especial ao paciente que fica internado por longos anos e a punição para a internação arbitrária ou desnecessária. Complementando esta, a Lei $n^{\circ} 10708$, de 2003, instituiu o auxílio reabilitação psicossocial para pacientes com transtornos mentais, o que consiste no "Programa de Volta para Casa", dando suporte ao processo de desinstitucionalização de pacientes com longo período de permanência no hospital psiquiátrico.

Foi neste contexto que o IPUB deu um passo inovador em direção às novas políticas de saúde mental, uma vez que diminuir o número de pacientes internados não significava somente dar alta ou não permitir novas internações. Era necessário planejar um ambiente assistencial de internação focado na reabilitação psicossocial dos indivíduos, de modo que conseguissem cuidar de si fora do ambiente hospitalar, contando com o suporte familiar e da rede de saúde mental. Neste sentido, a unidade de internação precisava tornar-se um espaço terapêutico, um dispositivo de favorecimento das relações sociais e do autocuidado (3).

Desde a sua criação, a distribuição dos pacientes internados no IPUB era por sexo, independente do quadro clínico, existindo uma enfermaria masculina (Enfermaria 1) e outra feminina (Enfermaria 2), onde conviviam pessoas com transtorno mental de diferentes tipos e em diferentes estágios. As normas de funcionamento da instituição determinavam os horários de medicação, de visita e de saída dos pacientes para o pátio externo. Os horários das refeições eram diferentes para cada enfermaria, o que acabava por evitar o encontro entre homens e mulheres no refeitório.

A implantação de Enfermarias Mistas propunha a substituição da distribuição dos pacientes internados por sexo, por uma distribuição por quadro clínico. Tal distribuição passou a alocar pacientes de ambos os sexos 
em quadro agudo, em uma enfermaria, e pacientes de ambos os sexos em quadro crônico ou estável, em outra (2).

O fato de se alojar pacientes de ambos os sexos na mesma enfermaria não implicava em acomodar homens e mulheres no mesmo quarto. Existiam quartos somente para mulheres, que ficavam em uma ala da enfermaria, e quartos somente para homens, que ficavam em outra ala da enfermaria, bem como banheiros masculino e feminino. O que passou a ser comum aos pacientes foi o pátio interno da enfermaria, sendo o grande diferencial da nova proposta o fato de não haver portas ou grades separando os homens das mulheres e sim o respeito às regras sociais e à privacidade alheia.

Surgiram muitos questionamentos sobre a viabilidade da nova proposta e a equipe de enfermagem, liderada pela chefe de enfermagem, que tinha também como colaboradores professores e alunos de graduação e pós-graduação da EEAN, passou por um processo de reconfiguração de suas práticas, ao planejar uma nova forma de cuidado ao doente mental internado, sem a segregação sexual imposta por barreiras físicas, o que sobrecarregava em responsabilidade a equipe de enfermagem do IPUB.

Essa modificação na lógica de alocação de pacientes foi planejada e preparada em reuniões multidisciplinares e de enfermagem, nas quais se encontravam os profissionais do serviço e da academia para discutir a melhor maneira de viabilizar a implantação das "Enfermarias Mistas" (5).

Tendo funcionado por seis anos, as Enfermarias Mistas representam um fato histórico relevante para a época em que foram implantadas, caracterizado por transformações tanto na configuração de unidades de internação psiquiátrica quanto na abordagem de assistência às pessoas com transtornos mentais internadas, uma vez que substituiu a separação por sexo, comum na maioria das unidades de internação psiquiátricas, por uma distribuição de acordo com o quadro clínico, o que representou uma mudança radical no ambiente das enfermarias e, consequentemente, no trabalho da equipe de saúde mental, em especial da enfermagem, 24 horas presente neste ambiente.

A extinção das Enfermarias Mistas deveuse a mudança de gestão no IPUB. A proposta da distribuição dos pacientes tinha opositores devido aos riscos que poderiam ocorrer, caso não fosse sustentada por profissionais comprometidos e especializados no cuidado em saúde mental. As linhas de atenção em saúde mental são diversificadas e, apesar do desenvolvimento da Reforma Psiquiátrica no Brasil, naquele momento se tinha uma divisão de opiniões a respeito das formas de atingir um cuidado psicossocial (5).

A curta trajetória das Enfermarias Mistas no IPUB envolveu muitas questões a serem abordadas sob a perspectiva histórica, que vão desde a sexualidade dos doentes mentais até os preconceitos sobre a doença mental, ambos fortes argumentos utilizados ao longo da história da psiquiatria para se negar a liberdade e a autonomia dessas pessoas. Tais temas são foco de outras pesquisas em desenvolvimento no âmbito do grupo de pesquisa, o que nos permitiu recortar o objeto de estudo proposto para este artigo, que tem como objetivo: analisar as implicações da implantação das "Enfermarias Mistas" na configuração do espaço assistencial do IPUB, na visão da equipe de enfermagem.

O estudo se justifica pelo registro histórico da vivência da equipe de enfermagem do IPUB em Enfermarias Mistas, experiência inédita na instituição. Embora tal experiência tenha sido vivenciada em outros hospitais, a revisão de literatura evidenciou que não há produção científica sobre o tema em quantidade expressiva.

O processo de transformar um espaço assistencial de internação psiquiátrica, atualmente em declínio no Brasil, é relevante porque evidencia parte de um processo histórico de desconstrução do manicômio e da psiquiatria tradicional, que durante longos anos 
segregou o paciente psiquiátrico em espaços onde também isolava-se homens de mulheres. A convivência entre seres humanos em sua totalidade e diversidade é importante fator de integração e convivência em sociedade. Desta forma, a experiência do IPUB retratada neste estudo, aponta para a desconstrução de preconceitos e estigmas com o doente e a doença mental.

\section{MÉTODO}

Estudo histórico-social, de natureza qualitativa, cujo marco inicial é o ano de 1996, quando foram implantas as Enfermarias Mistas no IPUB, e o marco final é o ano de 2002, quando as mesmas foram extintas, dando lugar ao sistema anterior de distribuição de pacientes por sexo. Neste estudo utilizamos como fontes primárias documentos escritos e orais e como fontes secundárias artigos publicados em periódicos científicos.

A história oral temática foi utilizada na produção das fontes orais, por sua pertinência quando investigamos o que ocorreu em um tempo relativamente recente e quando há falta de informações a respeito desse período, permitindo o registro de testemunhas e ampliando as possibilidades de interpretação do passado (6). Os colaboradores foram três enfermeiros e dois técnicos de enfermagem que trabalharam nas Enfermarias Mistas do IPUB, no período estudado. Estes profissionais tinham, em média, 10 anos de experiência no IPUB, na época da coleta de dados. Os mesmos estão identificados no texto com a letra inicial de sua profissão e número correspondente à ordem da entrevista.

A coleta de dados seguiu a técnica de entrevista semi-estruturada e as diretrizes do Conselho Nacional de Saúde/Ministério da Saúde, sendo este artigo um recorte do projeto: "Sistema de Enfermarias Mistas em Psiquiatria: memória da equipe de enfermagem (1996-2002)", aprovado nos Comitês de
Ética em Pesquisa da EEAN/Hospital Escola São Francisco de Assis/UFRJ (protocolo no 049/2011) e do IPUB (parecer no 12-Liv.4-11 FR 43976758/2011).

Após a coleta de dados as entrevistas foram transcritas e validadas pelos colaboradores que autorizaram a sua utilização na pesquisa. Para a análise realizou-se a leitura atenta e comparativa do material textualizado para que os fatos históricos explicitados pelos colaboradores fossem destacados como resultados. Estes foram organizados a partir da sua cronologia e temática, classificados em categorias, cuja análise foi sustentada por autores que tratam da história da enfermagem, bem como da saúde mental e da enfermagem psiquiátrica, na perspectiva da Reforma Psiquiátrica Brasileira (7).

\section{RESULTADOS}

\section{Surge um novo espaço terapêutico no IPUB: "Enfermaria de portas-abertas"}

Em 1996 foram implantadas as Enfermarias Mistas no IPUB, onde a distribuição dos pacientes passou a ser realizada de acordo com o quadro clínico e não mais pelo sexo. A nova proposta assumida em meio ao movimento de reforma psiquiátrica visava adequar o IPUB às legislações vigentes, o que tornava necessário aproximar o ambiente hospitalar da realidade social, facilitando a readaptação dos pacientes no pós-alta.

Sendo assim, a convivência entre homens e mulheres com transtorno mental nas Enfermarias Mistas passou a ser constante e as características de cada enfermaria relacionadas com o quadro clínico apresentado pelas pessoas nelas internadas. Essa nova configuração logo propiciou uma distinção entre as enfermarias, onde a Enfermaria 1, destinada a pessoas em quadro agudo ou crise, tinha suas portas trancadas à chave, que ficava de posse da equipe de enfermagem encarregada 
de abri-las quando necessário. A Enfermaria 2 , destinada a pessoas em quadro compensado, estabilizado ou crônico, mantinha suas portas abertas nos horários de visita e de pátio, permitindo a circulação dos pacientes entre enfermaria e pátio externo do IPUB.

$\mathrm{Na}$ fala a seguir, observamos a nova interpretação sobre a Enfermaria 2:

O que significava enfermaria de portas abertas? É que nos horários de refeição, de passagem de plantão e em alguns outros momentos, a porta da enfermaria era fechada, mas nos horários de visita, de pátio, essa porta ficava aberta (E2).

Vemos que a entrevistada usa a denominação "Enfermaria de Portas Abertas", para explicar o novo funcionamento da Enfermaria 2, que passava a refletir uma oposição ao modelo da psiquiatria tradicional bem caracterizado na história da loucura, onde portas trancadas, grades, cadeados e muros simbolizavam a exclusão social e o confinamento imposto pela instituição aos doentes mentais.

A saída de pacientes para o pátio externo era concedida através da prescrição médica e os horários estabelecidos institucionalmente eram de $9-11$ h e de $14-17 \mathrm{~h}$. Como era a condição clínica do paciente que determinava a prescrição de pátio pelos médicos, bem como a enfermaria da qual ele fazia parte, na Enfermaria 2 os pacientes tinham "pátio livre" enquanto na Enfermaria 1 a maioria dos pacientes tinha "pátio proibido" ou "pátio acompanhado". Desses, faz-se necessário explicar que, para as prescrições de "pátio acompanhado", os pacientes só podiam sair da enfermaria supervisionados por um membro da equipe de saúde, geralmente da enfermagem, ou por um familiar, sendo que nos horários de pátio, cabia ao paciente a decisão de quando sair ou retornar à enfermaria. $\mathrm{Ou}$ seja, o paciente de pátio acompanhado não era obrigado a cumprir os horários de pátio, mas era parte do cuidado de enfermagem o estímulo para que frequentassem ambientes externos à enfermaria como forma de reintegração social.

Cabia a equipe de enfermagem o controle de saída e retorno dos pacientes para o pátio, sendo que na Enfermaria 2 a porta era aberta no horário de início do pátio e fechada ao final, uma vez que, dentro desses horários, o paciente podia entrar e sair desacompanhado a qualquer momento que desejasse. A enfermeira era responsável por conferir o retorno de todos os pacientes à enfermaria antes de fechar a porta e por garantir que os pacientes de "pátio acompanhado" tivessem um técnico responsável durante todo o período de permanência fora da enfermaria.

A seguir, vemos como as Enfermarias Mistas propiciaram ao paciente a tomada de decisão sobre onde ficar em determinados momentos do dia:

\section{[...] Então, os pacientes tinham livre acesso da enfermaria para o pátio externo. O pátio ex- terno era dentro ainda do hospital, mas eles ti- nham o acesso livre de ir e vir (E2).}

Diferentemente disso, na Enfermaria 1, a equipe de enfermagem ficava responsável pela liberação somente do paciente de "pátio acompanhado", situação referida por alguns entrevistados como desagradável, porque os pacientes de pátio proibido questionavam e apelavam para que também pudessem sair, uma vez que viam os demais pacientes sendo liberados para o pátio externo.

Logo, nas Enfermarias Mistas era atribuído à enfermagem o papel de controlar o trânsito dos pacientes, conforme as regras institucionais e tipo de pátio estipulado pelo médico assistente, de acordo com a avaliação realizada pelo mesmo no momento em que esteve com o paciente pela última vez. No entanto,

[...] a avaliação diária do paciente era feita pela enfermeira que, quando notava alguma mudança no quadro do paciente, solicitava ao médico plantonista uma reavaliação, que mui- 
tas vezes resultava em alteração na prescrição do pátio (E1).

A posição de impedir que os pacientes agudos tivessem acesso ao pátio externo ainda era uma questão a ser solucionada a partir da experiência de "Enfermarias Mistas", sendo objeto de discussão em reuniões de equipe, coordenadas pela chefe de enfermagem à época.

Dentre as transformações vivenciadas durante o funcionamento das Enfermarias Mistas do IPUB, destaca-se a existência de dois espaços terapêuticos diferenciados, que influenciavam sobremaneira na assistência de enfermagem psiquiátrica, onde ainda se confundiam os papéis historicamente construídos e os novos papéis em construção:

\section{[...] a [enfermaria] de portas abertas é muito} boa, é como se fosse um presente, a gente dizia assim pro paciente: você tem que tomar um remédio, tem que melhorar porque você vai para outra enfermaria, você vai pra enfermaria $2, e$ isso pra eles era um presente, então eles tomavam remédio, tentavam se organizar pra poder passar para essa outra enfermaria, que nessa outra enfermaria eles tinham liberdade. 9 horas abria o pátio, aí só entravam 11horas. Tinha diferença de tratamento. Lá eles tinham mais roupas, podiam escolher roupas, era melhor o tratamento então (T1).

\section{Reflexões da equipe de enfermagem sobre a mudança nos espaços terapêuticos do IPUB}

Não há como negar as transformações no cuidado de enfermagem psiquiátrica decorrentes da implantação das Enfermarias Mistas, uma vez que, anteriormente, ambas as enfermarias do IPUB eram de "portas fechadas", porque abrigavam pacientes em diferentes estágios de sofrimento psíquico.

A possibilidade de "destrancar" uma das enfermarias já representou uma ruptura no antigo modelo, ou seja, uma enfermaria com pessoas com transtornos mentais em qua- dros estabilizados permitia maior autonomia à pessoa internada, bem como melhores condições para a realização do cuidado de enfermagem e da assistência como um todo, uma vez que a internação passava por diferentes fases até a alta.

Alguns entrevistados falaram a respeito da interferência da organização das unidades de internação por quadro clínico na rotina hospitalar, uma vez que foi possível se ter uma enfermaria de "portas abertas", diminuindo assim o isolamento de pacientes em quadros estabilizados, comparando com o antigo sistema de divisão por sexo onde os mesmos ficavam sem liberdade por conta da situação aguda de outros:

Não tinha mais aquele idoso com Alzheimer misturado com um paciente maníaco, um homem com transtorno bipolar ou um homem esquizofrênico em delírio, agressivo, que isso acontecia quando a enfermaria era por sexo. Então tinha doentes alcoolistas, idosos com Alzheimer, misturados com pacientes que empurravam, batiam, agrediam, tiravam a comida dele. Então, isso foi uma coisa, um ponto positivo, você tem pacientes de acordo com seu quadro, então a convivência, a proteção ao doente é mais fácil pela enfermagem (E1).

Dessa forma, a experiência nas Enfermarias Mistas permitiu uma reflexão da equipe de enfermagem quanto à influência da convivência entre pessoas em diferentes fases de adoecimento psíquico no cuidado:

[...] os pacientes que estão mais agudizados eles requerem uma atenção mais direta, mais integral, o tempo todo de várias pessoas. (....) colocar as pessoas agudas com pessoas que estão há quatro anos morando em uma instituição é muito complicado (....) acho que um acaba prejudicando o processo de melhora do outro, quando a divisão das enfermarias é por sexo (E3).

No comentário a seguir, vemos que a 
equipe de enfermagem do IPUB tinha preparo teórico e prático para assumir os desafios da nova proposta:

[...] Mas a questão não é agudo ou crônico,o agudo vai exigir um cuidado mais intensivo, o problema é você deixar todos os pacientes lá nas enfermarias e ficar numa outra sala a parte, aí será um problema. Agora, se a equipe está preocupada, tem uma proposta terapêutica, tem um projeto para os pacientes, se tem atividades, tem um acompanhamento de perto, isso não é problema, agora, com certeza, para os pacientes moradores, os pacientes crônicos, é muito mais danosa a divisão por sexo (E3).

Neste estudo ficou evidente que um ganho obtido com a proposta de Enfermarias Mistas veio da separação dos doentes agudos dos doentes crônicos ou estabilizados. Outro ganho observado é no comportamento dos pacientes, quando em convivência com o sexo oposto:

[.... eu acho que eram pontos muito positivos, né? De se assemelhar mesmo o que a gente vivencia do lado de fora de uma internação, com essa convivência com os diferentes gêneros (E2).

Um serviço psiquiátrico de qualidade deve apresentar um campo de possibilidades que se reorganizam cotidianamente, tendo em vista a garantia da reabilitação dos clientes, nos seus limites e potencialidades individuais.

\section{DISCUSSÃO E CONCLUSÃO}

As proposições de reforma psiquiátrica apontam que os serviços comunitários não substituem a instituição hospitalar, pois fazem compreender o sistema de saúde mental como um circuito em que existe uma relação de complementaridade entre as estruturas na comunidade e as de internação. Dessa forma, a estática da segregação do modelo asilar é substituída pela dinâmica de circulação da demanda nos diferentes serviços especializados, sendo os locais de internação necessários, seguindo a lógica de que devem ser reabilitadores e temporários (8).

Com a implantação das Enfermarias Mistas, a Enfermaria 1 passou a ser denominada Enfermeira Teresa de Jesus Sena e a Enfermaria 2, Dr. Adolpho Hoirich, ambos ilustres personagens que tiveram destaque na trajetória do IPUB. Respectivamente, a primeira enfermaria passou a receber pacientes em quadros agudos e a segunda, pacientes em quadros estáveis ou crônicos (2).

A psiquiatria ainda tem dificuldade em estabelecer os limites dos conceitos de enfermidade aguda e crônica. Contudo, tais conceitos têm importância clínica suficiente para justificar seu emprego (9) e são definidos da seguinte maneira: "Paciente agudo é o que está passando por uma crise, um surto, que, em linguagem psiquiátrica, caracteriza-se por sintomas negativos (perdas ou diminuição em suas funções psíquicas) e por sintomas positivos (discurso desorganizado, presença de delírios e/ou alucinações). O paciente crônico é o que tem uma história de internamentos reincidentes que vêm acontecendo ao longo do tempo ou aquele que se encontra internado há vários anos na instituição, podendo ou não apresentar sintomas psiquiátricos" (10).

Cabe ressaltar que o pátio externo do IPUB é uma área comum a todos que entram na instituição (profissionais, alunos, clientes, visitantes) e que possui cantina, estacionamento, acesso para a biblioteca, hospital-dia, salas de aula, setor administrativo, entre outros. A ida ao pátio permitia aos pacientes internados o encontro com diferentes pessoas e também a participação em atividades do hospital-dia, caso desejassem. Desta forma, o que denominamos pátio externo tem características de "lado de fora" do hospital, quando se tem como referência o modelo asilar (10). 
Percebemos que a diferença estabelecida pelo novo sistema de distribuição de pessoas com transtornos mentais, fazendo existir uma enfermaria de "portas-abertas" e outra de "portas fechadas" interferia no tratamento porque era usado pela equipe como forma de barganha, o que ainda se assemelhava ao antigo papel da enfermagem psiquiátrica em que o doente era punido por apresentar os sintomas de sua doença.

Porém, sabemos que as mudanças assistenciais até hoje produzidas nos espaços de internação psiquiátrica têm sua própria trajetória e que não houve, na experiência do IPUB, a possibilidade de se romper imediatamente com as antigas práticas (11). Podemos também avaliar nos resultados da pesquisa que a necessidade de mudança no quadro clínico para que houvesse a transferência do paciente para a enfermaria de "portas abertas" servia de estímulo para que o mesmo aderisse ao tratamento para mudar para um ambiente menos controlado.

Para a existência de uma "enfermaria de portas abertas" era necessário um trabalho multidisciplinar, uma vez que, mesmo em quadros psiquiátricos estáveis, crises podem ocorrer, apesar da manutenção de um plano terapêutico, levando um paciente estável ou compensado a um quadro agudo (10). Por isso, para a assistência aos pacientes em ambas enfermarias deveria se considerar a responsabilidade do cuidado nos diferentes momentos de sofrimento psíquico, o que implicava em atenção intensiva e contínua. Tratava-se de compreender que na prática cotidiana também era necessário "dialetizar, decompor, desconstruir a demanda de internação no hospital psiquiátrico" (8).

Nesse sentido, como parte de um planejamento de transformação da assistência prestada, a chefe de enfermagem implantou outros espaços terapêuticos que integravam os pacientes internados com os demais, sem nenhuma segregação sexual. A equipe de enfermagem se engajou para fazer funcionar um salão de beleza, montado em um espaço específico na Enfermaria 2, uma assembleia de pacientes, que funcionava como espaço de escuta e de discussão sobre temas escolhidos pelos pacientes, inclusive sobre as Enfermarias Mistas, e um baile de pacientes (12).

Tais espaços reconfiguraram a rotina das enfermarias possibilitando maiores oportunidades para o desenvolvimento do processo de reabilitação psicossocial ao dar opções de ambientes, de distração, de integração e, especialmente, de cuidado, uma vez que a equipe de enfermagem planejava, executava e avaliava tais atividades (12).

Os demais profissionais da equipe de saúde não tiveram participação significativa no funcionamento desses espaços, mas, médicos, psicólogos e assistentes sociais participavam em alguns momentos dos mesmos e expressavam apoio a sua existência. Esse apoio da equipe multiprofissional do IPUB foi muito importante e permitiu que a enfermagem ficasse diretamente responsável por conduzi-los como espaços terapêuticos. Também destaca-se que haviam profissionais contrários as mudanças porque seguiam ainda a lógica da psiquiatria tradicional (5).

A partir da Reforma Psiquiátrica, a assistência aos pacientes psiquiátricos vem apresentando algumas transformações, dentre as quais está o deslocamento da loucura vista como o "centro", para um sujeito com aspirações, direitos e projetos, integrante de uma família e membro de uma determinada comunidade. Assim, a partir desse marco na história da psiquiatria, os profissionais de saúde não passam a destacar o atendimento individual ao doente e sim, seus relacionamentos afetivos, sociais, familiares e comunitários (13).

Eleger a reabilitação social como paradigma de um novo método de cuidado em saúde mental é defender ações que privilegiem as preferências dos usuários e familiares, respeitando as suas subjetividades, além da valorização da coparticipação e da corresponsabilidade dos mesmos (13).

Ao nos debruçarmos sobre o Hospício de 
Pedro II (HPII), em 1852, primeiro da América Latina, que além da separação sexual, tinha outras que incluíam a classe social e o comportamento dos doentes, vemos que se pensava nessa questão da convivência entre doentes em diferentes fases do adoecimento psíquico, comentada pelos entrevistados nessa pesquisa (14). No entanto, no IPUB, onde o espaço era reduzido em comparação ao HPII, construído com capacidade para abrigar 350 doentes mentais, não era possível separar dentro das enfermarias femininas e masculinas os quadros clínicos (14). Soma-se a essa dificuldade a proposta da reforma psiquiátrica de não se manter grandes hospitais psiquiátricos, nem elevado número de internações de longa permanência.

A presença do hospital psiquiátrico não implica na obrigatoriedade de uma total exclusão social. Assim, consequentemente, a existência da unidade de internação hospitalar; localizada no hospital, não implica na sua filiação ao modelo manicomial $(15,16)$.

Para atender as transformações impostas pela Reforma Psiquiátrica, as instituições modificaram o espaço assistencial de internação, a fim de preparar o doente mental para o convívio social, minimizando os efeitos negativos da internação. Nesse sentido, o IPUB já mostrava uma preocupação com a não institucionalização do paciente e na melhoria na assistência de enfermagem nesse espaço institucional, lutando para transformá-lo em um espaço comum de tratamento, em substituição ao local de segregação social.

Em conclusão o recorte temporal deste estudo representa um marco na história da psiquiatria no Brasil, bem como na trajetória da assistência da enfermagem psiquiátrica, por ter sido uma experiência singular, dentro do movimento de reforma psiquiátrica vivenciado no IPUB, uma instituição historicamente marcada pela busca de novas práticas e modelos para melhor atender o doente mental.
A partir de 1996, a nova experiência de modelo de internação com a implantação das Enfermarias Mistas, ocasionou uma mudança radical no espaço assistencial do IPUB, uma vez que a separação de doentes por quadro clínico levou a mudanças nas formas de intervenção e tratamento em cada enfermaria. Ao mesmo tempo, exigiu da equipe de saúde maior planejamento das ações de saúde e comprometimento com a mudança que se estabelecia como possibilidade de criar uma nova assistência psiquiátrica, garantindo e respeitando o paciente em sua individualidade durante a internação hospitalar, ao mesmo tempo em que se preocupava com a sua segurança e integridade física, a fim de prepará-lo para a vida fora do hospital.

A equipe de enfermagem do IPUB foi o principal agente transformador nesse movimento, liderado pela chefe de enfermagem da instituição, que apostava na capacidade de reabilitação psicossocial dos doentes internados, a partir de uma convivência o mais próximo possível da realidade em que vivemos.

Vimos que a implantação das Enfermarias Mistas no IPUB propiciou o surgimento de um espaço terapêutico diferenciado e facilitador da reabilitação psicossocial, uma vez que fez surgir uma enfermaria de "portas abertas". No entanto, a equipe de enfermagem ainda permaneceu com papéis de vigilância e controle em ambas as enfermarias, porém com maior liberdade para o planejamento de suas ações em busca da manutenção de um ambiente mais próximo da realidade social.

As enfermarias mistas transformaram o espaço assistencial e permitiu a enfermagem psiquiátrica do IPUB oferecer ao doente internado uma assistência mais humanizada e atenta as suas necessidades, que fugia do antigo modelo a excludente e impeditivo do convívio entre pessoas de ambos os sexos. Embora tenha sido extinta, fica neste artigo o registro desse fato histórico que permite novas investigações sobre o tema. 


\section{REFERÊNCIAS}

1. Silva Filho J. O Instituto de PsiquiatriaIPUB/UFRJ. Cadernos IPUB. 1998; (n.esp.) 11-13.

2. Miranda CML. Algumas questões sobre assistência de enfermagem psiquiátrica de qualidade. Por uma assistência psiquiátrica em transformação. Cadernos IPUB. 1999; (3): 95-101.

3. Pinho LB, Hernández AMB, Kantorski LP. Concepção de clientela: análise do discurso da benevolência no contexto da Reforma Psiquiátrica Brasileira. Rev Bras Enferm. 2010; 63(3): 377-84.

4. Oliveira FB, Fortunato ML. Saúde Mental: reconstruindo saberes em enfermagem. Rev Bras Enferm. 2003; 56(1): 6770.

5. Bandeira PM, Souza $\mathrm{CH}$, Guimarães JCS, Almeida Filho AJ, Peres, MAA. Psychiatric Nursing in Integrated Wards Accommodating Both Female and Male Patients: A Historic Pioneering Reform Initiative Implemented by the Institute of Psychiatry, a Unit of the Federal University of Rio de Janeiro, Brazil. Issues Ment Health Nurs. 2015; 36(10): 791-798.

6. Alberti V. Manual de História Oral. $3^{\mathrm{a}}$ ed. Rio de Janeiro: FGV; 2005. 236 p.

7. Coutinho CP. Metodologia de investigação em ciências sociais e humanas. $2^{\mathrm{a}} \mathrm{ed}$. Coimbra (pt): Almedina; 2013. 421 p.

8. Nicácio F, Campos GWS. A complexidade da atenção às situações de crise - contribuições da desinstitucionalização para a invenção de práticas inovadoras em saúde mental. Rev. Ter. Ocup. Univ. São Paulo. 2004; 15(2): 71-81.
9. Junior MS, Salvador L. Compêndio de Psicopatologia e Semiologia Psiquiátrica. $1^{\text {a }}$ ed. Porto Alegre (RS): Artimed; 2001. $440 \mathrm{p}$.

10. Carneiro NGO, Rocha, LC. O processo de desospitalização de pacientes asilares de uma instituição psiquiátrica da cidade de Curitiba. Psicol. cienc. prof. 2004 Set; 24(3): 66-75.

11. Peres MAA, Barreira IA. Desenvolvimento da assistência médica e de enfermagem aos doentes mentais no Brasil: os discursos fundadores do hospício. Texto contexto - enferm. 2009 Out-Dez; 18(4): 635-642.

12. Peres MAA, Morandini GM, Ferreira OS, Miranda CML. Salão de beleza: uma proposta de reabilitação psicossocial? Arq. Bras. Psiquiatr. Neurol. Med. Legal. 2000; SI (72): 33-40.

13. Azevedo DM, Miranda FAN. Oficinas Terapêuticas como Instrumento de Reabilitação Psicossocial: Percepção de Familiares. Esc Anna Nery. 2011; 15(2): 339-345.

14. Peres MAA, Barreira IA, Santos TCF, Filho AJA, Oliveira AB. O ensino da psiquiatria e o poder disciplinar da enfermagem religiosa: o hospício de Pedro II no segundo reinado. Texto contexto - enferm. 2011; 20(4): 700-708.

15. Casanova EG, Porto IS, Figueredo NM. O cuidado de enfermagem familiar / exótico na unidade de internação psiquiátrica: do asilar para a reabilitação psicossocial. Esc Anna Nery. 2006; 10(4): 635-644.

16. Happell B. A better way to do this? Views of mental health nursing directors about preparation for mental health nursing practice. Aust Health Rev. 2015; 39(2): 211-216. 